\title{
Thermoeconomic Optimization Of A Boiler Used In A Coal Fired Thermal Power Plant Based On Hot Air Temperature
}

\author{
Mukesh Gupta ${ }^{1}$ and Raj Kumar ${ }^{2}$ \\ ${ }^{1,2}$ Department of Mechanical Engineering, YMCA University of Science \& Technology \\ Faridabad, Haryana, India
}

\begin{abstract}
The purpose of this study is to analyze the effect of hot air temperature on the thermoeconomic performance of a boiler used in a coal fired thermal power plant. Thermoeconomic model of the boiler is developed based on second law of thermodynamics. Performance analyses, based on exergoeconomic criteria, are done for the boiler used in a $55 \mathrm{MW}$ power plant. An example has been used to illustrate the methodology. Effect of air pre-heater temperature on the exergetic efficiency of the boiler system, unit product cost of the boiler and unit product cost of air pre-heater have been shown in detail. Optimization has been done for the boiler system as a trade off between the unit product cost of hot air and unit product cost of the boiler system. The outcomes of this study provide a useful basis for boiler performance analysis and improvement.
\end{abstract}

\section{Keywords}

Thermoeconomic Performance, Exergy, Boiler System \& Exergetic Efficiency

\section{Introduction}

A boiler is a device used to convert water to steam. The water to be converted to steam comes from two major sources: (1) Condensed steam returned from the processes. (2) Makeup water. Energy conservation systems have been studied in detail using the exergoeconomic analysis. In this direction many researchers have taken keen interest to prove the importance of this technique. Exergoeconomics has been used as a design tool for the realization of a gas turbine power plant principle [1]. Thermoeconomic technique has been used to optimize single and double effect vapor absorption refrigeration system [2, 3, 4]. Exergoeconomic analysis and optimization of the cycle of a co-generation system has been done. [5]. The strategy for optimizing the thermal system using the exergetic cost theory and symbolic exergoeconomics has been explained in detail by many reserachers [6, 7]. Many scholars have illustrated the benefits of exergoeconomic analysis and optimization using the exergy- related variables [8]. Several thermodynamic relations have been developed to illustrate the relationship between the energy and exergy losses and capital cost for thermal systems in a modern coal fired electrical generation station $[9,10,11$, $12,13]$. 


\section{Methodology}

\subsection{Boiler system}

The boiler system comprises of three sub systems, the feed water system, steam system and fuel system. The major streams entering and leaving the boiler have been depicted in Fig. 1

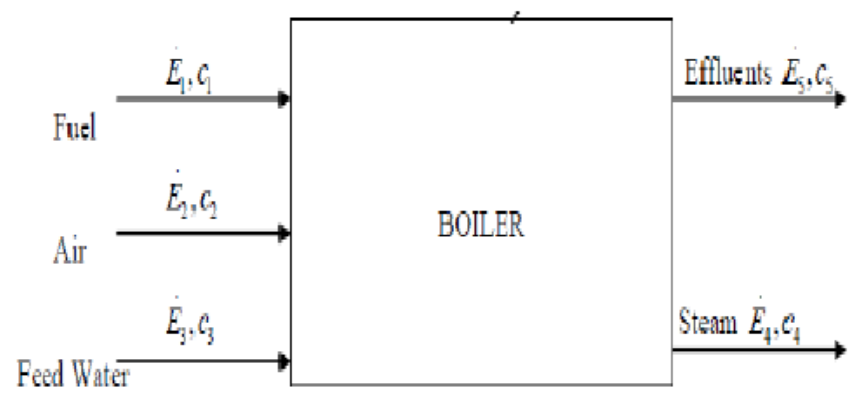

Figure 1. Different streams for a boiler system

The exergetic efficiency of a boiler is given as

$$
\varepsilon_{B}=\frac{E_{P, B}}{E_{F, B}}
$$

\subsection{Exergoeconomic Analysis}

Average costs per exergy unit of fuel and product for a boiler are given as

$$
\begin{gathered}
c_{F, B}=\frac{C_{F, B}}{E_{F, B}} \\
c_{P, B}=\frac{C_{P, B}}{E_{P, B}}
\end{gathered}
$$

The optimization process for the boiler involves the following assumptions:

1. The exergy flow rate from the boiler is constant.

2. The unit cost rate for fuel is taken as constant.

The exergy costing equation for the boiler is established as per Fig. (2) and is given as

$$
\mathrm{c}_{1} \dot{E}_{1}+\mathrm{c}_{2} \dot{E}_{2}+\mathrm{c}_{3} \dot{E}_{3}=\mathrm{c}_{4} \dot{E}_{4}+\mathrm{c}_{5} \dot{E}_{5}
$$

From the above equation, unit cost of product for boiler is calculated as:

$$
\mathrm{c}_{4}=\left[\mathrm{c}_{1} \dot{E}_{1}+\mathrm{c}_{2} \dot{E}_{2}+\mathrm{c}_{3} \dot{E}_{3}-\mathrm{c}_{5} \dot{E}_{5}\right] / \dot{E}_{4}
$$

In the exergoeconomic analysis and optimization process all the variables are taken as constant and the effect of hot air temperature coming from the air pre- heater on the unit product cost of boiler and exergetic efficiency of the boiler are studied and analysed. 


\section{Illustrative Example}

The above said methodology is explained with the help of an example in which a 55 MW power plant is considered. The schematic layout of the boiler system is shown in Fig. 1. For the boiler system under consideration, the values for various unit exergy costs are calculated as per Fig. 2 and are given in Table 1.

Table 1. Values of unit costs for different streams for a boiler

\begin{tabular}{|c|c|c|}
\hline S. No. & Stream No. & Unit exergy cost $(\mathbf{c})(\mathbf{R s} / \mathbf{k J})$ \\
\hline 1 & 1 (fuel) & 0.0950 \\
\hline 2 & 2 (hot air) & 0.2241 \\
\hline 3 & 3 (feed water) & 0.3362 \\
\hline 4 & 5 (effluents) & $0.0950^{*}$ \\
\hline
\end{tabular}

* For the stream exiting to atmosphere, the unit exergetic cost is taken to be same as the input cost of fuel. The range of temperature for the hot air is taken from $600 \mathrm{~K}$ to $620 \mathrm{~K}$.. Coal used in the plant is lignite with calorific value of $25427 \mathrm{~kJ} / \mathrm{kg}$.

\section{Results and discussion}

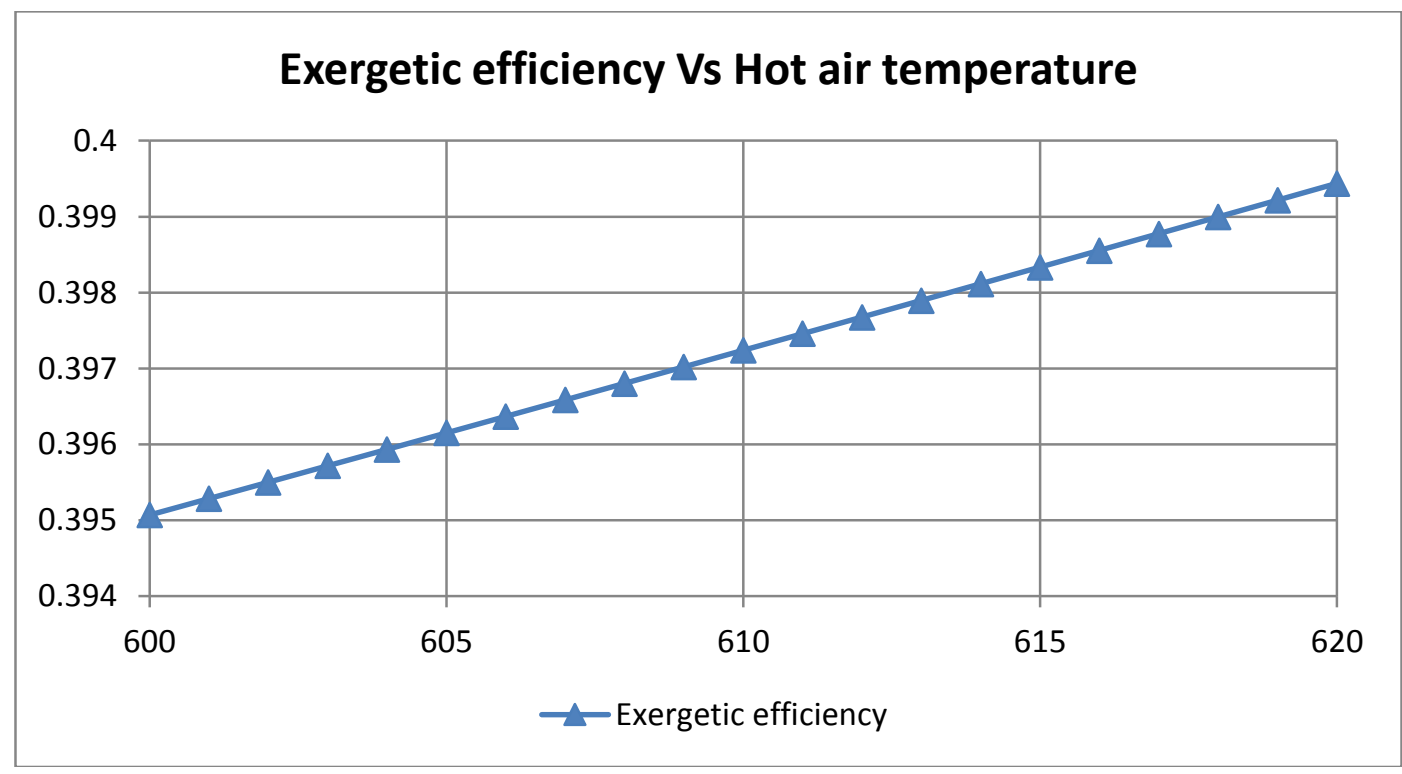

Figure 2. Variation of exergetic efficiency with hot air temperature 


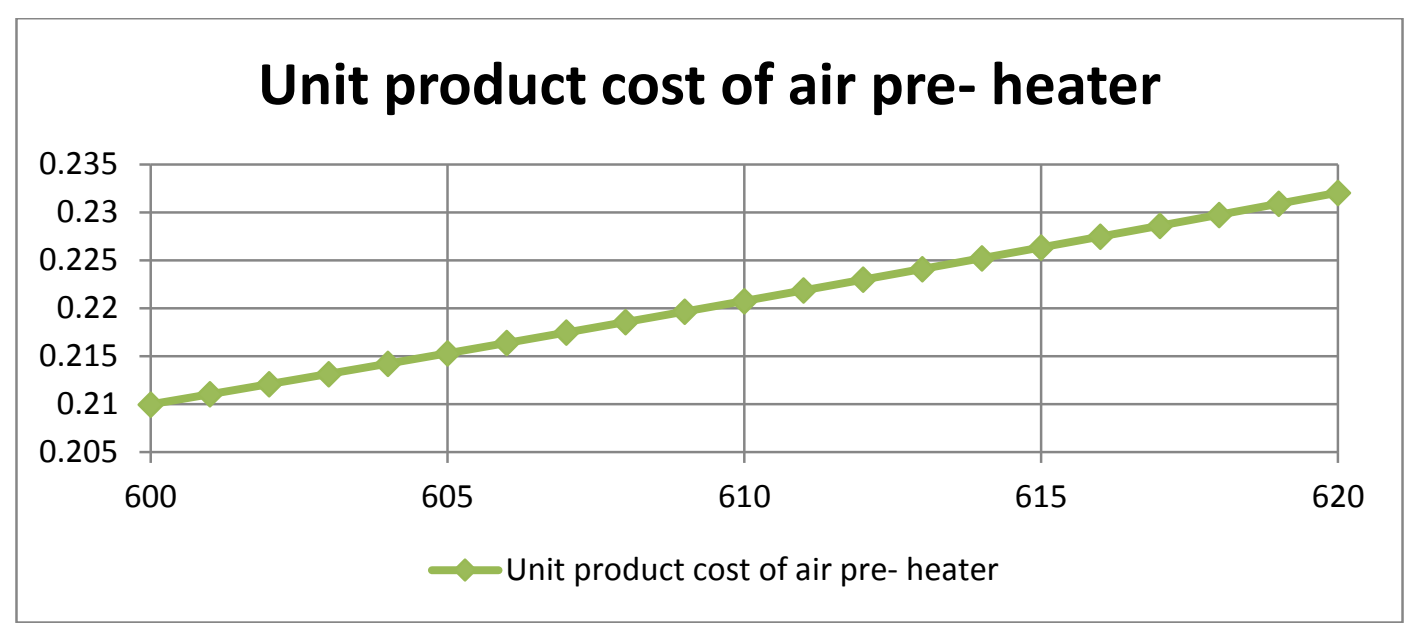

Figure 3. Variation of Unit product cost of air pre- heater with hot air temperature

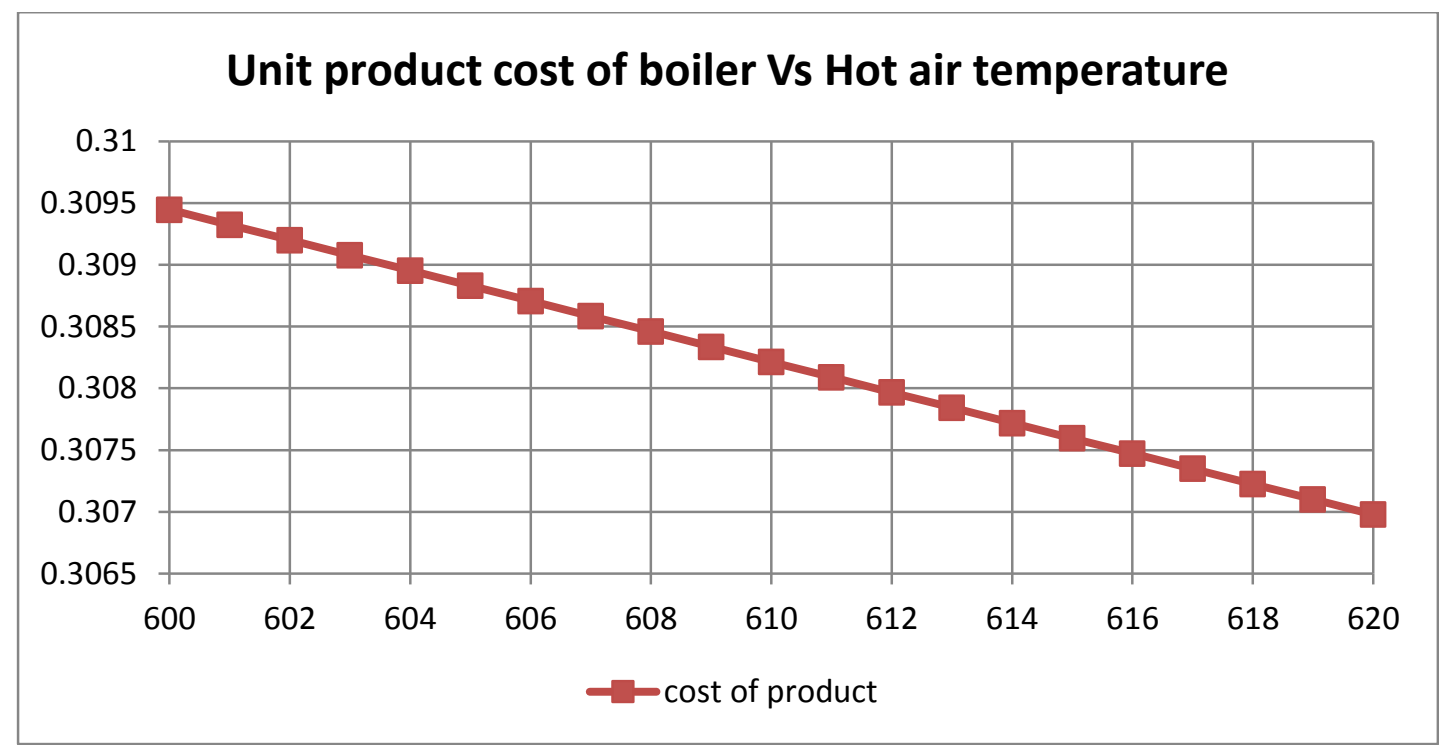

Figure 4. Variation of unit product cost of boiler with hot air temperature

The first step in the thermoeconomic process is to study and analyse the effect of hot air temperature on the exergetic efficiency of the boiler. Fig. 3. shows the effect of hot air temperature on the exergetic efficiency of the boiler system. Exergetic efficiency increases with an increase in the hot air temperature. This happens because for producing the same heating effect less exergy is required from the fuel.

The second step is to study and analyse the variation of unit product cost of air pre- heater with changes in the hot air temperature. Results of this variation are given in Fig. 4. The unit product cost of air pre- heater increases with the increase in the hot air temperature. This happens because to provide air at a higher temperature more money has to be spent.

The final step in the thermoeconomic process is to study and analyse the variation of unit product cost of boiler with hot air temperature. Increase in the hot air temperature results in lower unit product cost of boiler because to produce the same heating effect less fuel is needed resulting in lower fuel costs. Hence the overall unit product cost of the boiler decreases. 
Combined analysis of the previous two steps given in Fig. 5 shows that, whereas unit product cost of air pre- heater increases with an increase in the hot air temperature, the unit product cost of boiler decreases. To achieve the optimal solution a trade off has to be made between the unit product cost of the air pre- heater and the unit product cost of the boiler system. This optimal state appears where the two curves are intersecting. At this point the hot air temperature is found to be $609 \mathrm{~K}$ and the unit product costs for the boiler and the air pre- heater are found to be 0.3077 $\mathrm{Rs} / \mathrm{MJ}$ and $0.219 \mathrm{Rs} / \mathrm{MJ}$. For achieving further reduction in unit product cost of the boiler more money would have to be spent to provide air at higher temperatures thereby increasing the overall unit product cost of the boiler system.

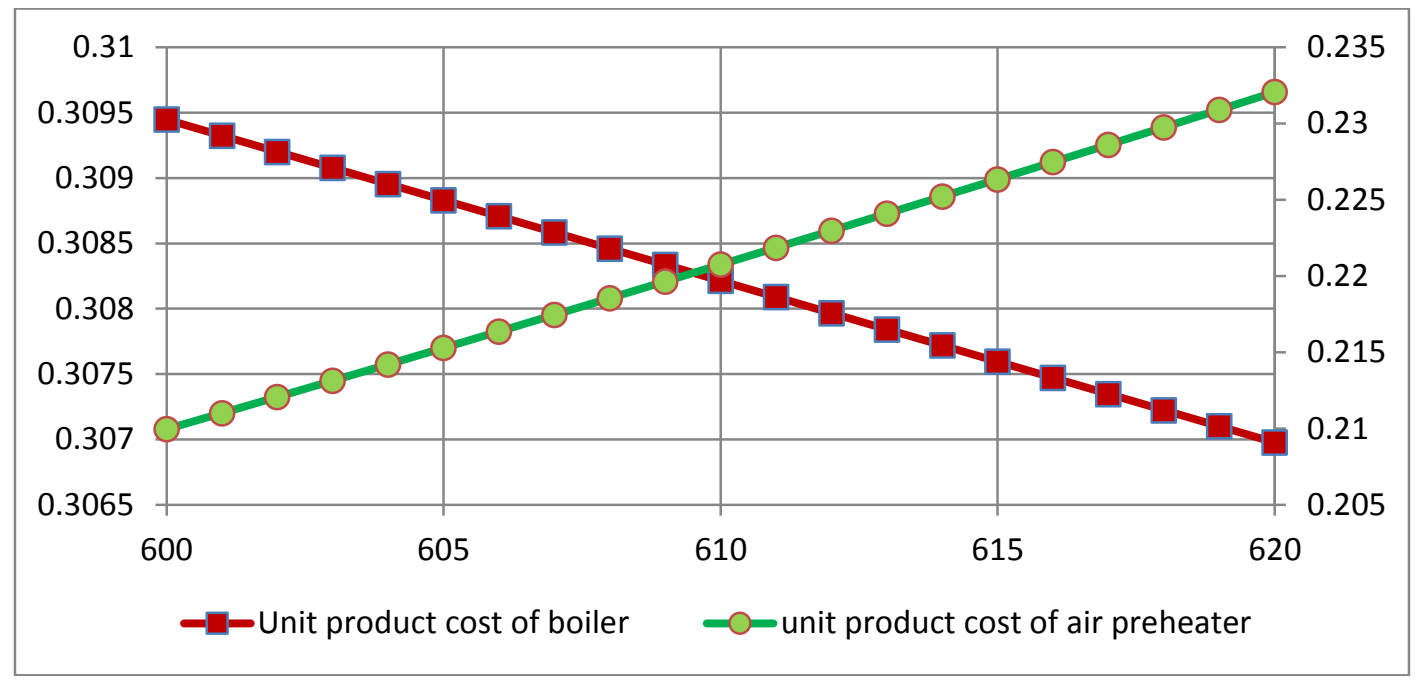

Figure 5. Combined effect of hot air temperature on unit product cost of boiler and air pre- heater

Based on the results of the study exponential relations have been developed for exergetic efficiency of the boiler system, unit product cost of air pre- heater and unit product cost of the boiler system as functions of hot air temperature. Eqns. (6), (7) and (8) illustrate these relationships.

$$
\begin{aligned}
& \varepsilon_{\mathrm{B}}=0.2841\left(1.0005^{\wedge} \mathrm{T}_{\mathrm{HA}}\right) \\
& \mathrm{c}_{\text {aph }}=0.0104\left(1.345^{\wedge} \mathrm{T}_{\mathrm{HA}}\right) \\
& \mathrm{c}_{\mathrm{B}}=0.3936\left(0.9996^{\wedge} \mathrm{T}_{\mathrm{HA}}\right)
\end{aligned}
$$

The above relations have been tested for different temperature ranges of hot air and the results obtained from them have been satisfactory with small variations as the process variables change. These relations reduce the calculation time and have been found to be very useful in quick thermoeconomic analysis of boiler performance. 


\section{Conclusions}

This study makes use of this concept of exergoeconomics to analyse the boiler system used in a coal fired thermal power plant. It shows in detail the effect of hot air temperature on the performance of the boiler system.

Effect of hot air temperature on exergetic efficiency of the boiler, unit product cost of air preheater and unit product cost of the boiler have been carefully studied and analysed. Optimization of the boiler system has been achieved on the basis of the fact that unit product cost of hot air increases with increase in its temperature and the unit product cost of boiler system decreases with the same. An optimal state has been achieved which provides the optimal value of the hot air temperature at which the hot air should be delivered to the boiler system.

Finally, a series of exponential relations have been developed which correlate the hot air temperature to the exergetic efficiency, unit product cost of the hot air and the unit product cost of the boiler. The validity of these correlations has been checked for different temperature range and it has been found that these relations provide a robust correlation model to analyse the boiler system with minor variations as a result of the process variables.

This study provides a robust model and excellent means to analyse the thermoeconomic performance of the boiler system with respect to the hot air temperature.

\section{References}

[1] Attala, L., Facchini, B., Ferrara, G. (2001) Thermoeconomic optimization method design tool in gassteam combined plant realization, Energy Conversion and Management 42 18, pp. 2163-2172.

[2] Mishra R.D., Sahoo P.K. and Gupta A., (2002) Application of exergetic cost theory to LiBr/H2O vapour absorption system, Energy, 1009-1025.

[3] Mishra R.D., Sahoo P.K. and Gupta A., (2003) Thermoeconomic optimization of single effect water/ $\mathrm{LiBr}$ vapour absorption refrigeration system, International Journal of Refrigeration, 26, 158-169.

[4] Mishra R.D., Sahoo P.K. and Gupta A., (2005) Thermoeconomic optimization of double effect water/ $\mathrm{LiBr}$ vapour absorption refrigeration system, International Journal of Refrigeration, 28, 331-343.

[5] Sahoo P.K.,, (2008) Exergoeconomic analysis and optimization of a cogeneration system using evolutionary programming, Applied Thermal Engineering, 28, 1580- 1588.

[6] Valero A. and Torres C., (2004) On causality in organized energy systems: II. Symbolic exergoeconomics, University of Zaragoza, Spain.

[7] Valero A., Lerch F., Serra L. and Royo J., (2002) Structural theo-ry and thermoeconomic diagnosis: Part II, Application to actual power plant, Energy Conversion and Management, 43, 1519-1535.

[8] Moran M.J. and Sciubba E., (1994) Exergy analysis: Principles and practice, Journal of Engineering for Gas Turbines and Power, 116, 285-290.

[9] Rosen M., (2002) Clarifying thermodynamic efficiencies and losses via exergy, Exergy International Journal, 2, 3-5.

[10] Rosen M., (2001) Editorial-Exergy in industry: Accepted or not? Exergy, An International Journal, 2 , 67.

[11] Rosen M., (2001) Energy and Exergy based comparison of coal fired and nuclear steam power plants, Exergy International Journal, 3, 180-192.

[12] Rosen M., (2002) Energy crisis or exergy crisis?, Exergy, An International Journal, 2, 125-127.

[13] Rosen M. and Dincer I., (2003) Thermoeconomic, Analysis of power plants: an application to a coal fired electrical generating station, Energy Conversion and Management, 44, 2743-2761.

[14] Bejan A., Tsatsaronis G. and Moran M., (1996) Thermal Design and Optimization, New York: Wiley. 